\title{
Updating existing railway bridges based on monitoring data
}

\author{
E. Brühwiler, M. Rocha \& M.A. Treacy \\ École Polytechnique Fédérale de Lausanne (EPFL), Switzerland
}

T.N. Bittencourt \& A.P.C. Neto

University of São Paulo, Brazil

\begin{abstract}
Due to ever increasing traffic demands the fatigue safety and service life of the bridges of a railway line in Brazil need to be examined. Conventional assessment methods using load models and approaches as suggested in codes lead to conservative results resulting in significant strengthening interventions. Due to the important direct and indirect costs of the intervention, more detailed examination methods based on data as obtained from monitoring is suggested. This paper reports on an ongoing study to examine the fatigue safety of one standard bridge type, i.e. riveted steel truss structure. First results show that all bridge members are safe under the various limit states. The level of stress ranges found in the truss members due to fatigue loading are low such that only two members experience fatigue damage. The bridge structure has thus significant reserves in capacity which makes a future increase in axle loads feasible.
\end{abstract}

\section{INTRODUCTION}

Due to ever increasing traffic demands the fatigue safety and service life of the bridges need to be examined. Conventional assessment methods using load models and approaches as suggested in codes often lead to conservative results resulting in significant strengthening interventions. Due to the important direct and indirect costs of such interventions, more detailed examination methods including data as obtained from bridge monitoring are justified and needed.

This paper reports on an ongoing examination of the fatigue safety of bridges within a network of railroads in Brazil used for the transportation of mineral ore. In particular, the fatigue safety and remaining fatigue life of a type of riveted steel truss bridge that was built in 1940 as standardized bridge type is treated.

A comprehensive numerical study based on the principles of a standard regarding existing structures (Brühwiler et al. 2011, Standard SIA 269 2011) has been carried out. The first objective was to examine the various types of locomotives and wagons traversing the bridge and develop appropriate load models. Results of in-situ measurements of the structural behaviour due to the passage of real trains in 2009 are used to calibrate a structural model to examine the load effects associated with these vehicles. After analysis of the structure and determination of the various member actions, structural safety verifica- tion checks were carried out for the ultimate, fatigue and service limit states.

\section{DESCRIPTION OF THE STRUCTURE}

The steel truss under investigation (Fig. 1) has a single span of $41 \mathrm{~m}$ and is in service since 1940 . It carries a single railway track which is trafficked by mineral ore trains.

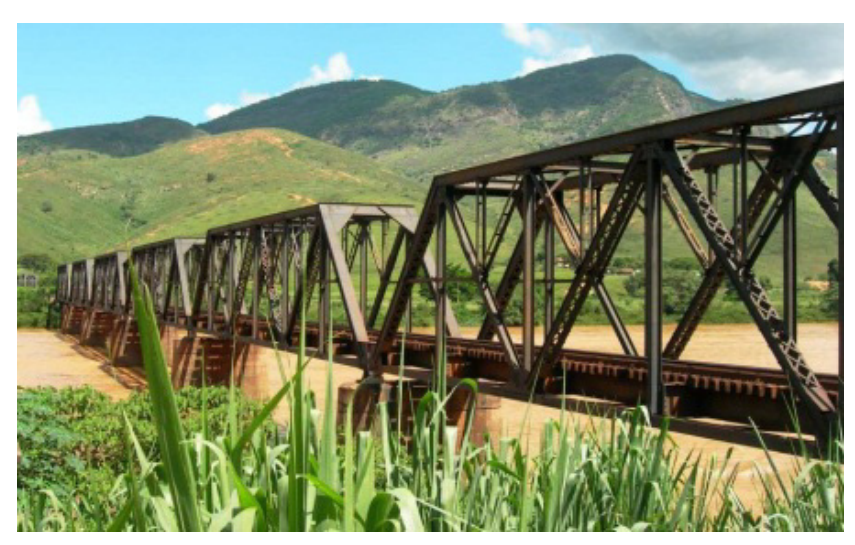

Figure 1. Viaduct composed of single span standard steel trusses.

The structure consists of two steel throughWarren trusses, $7.8 \mathrm{~m}$ in height, on either side of the bridge. The deck is of open grillage form with transverse floor beams connected to the side trusses and 
supporting the longitudinal stringers. The railway sleepers span between the stringers. The roof contains cross beams at the node points on the top chord of the trusses and cross-bracing members. Crossbracing is also provided on the underside of the deck grillage. Truss members are connected at the nodes by means of riveted steel plates. The end diagonals of the truss have portal connections to the roof beam in the transverse direction of the bridge for horizontal stability. The bridge is supported on pillars with one end fixed in direction and a sliding connection on the other end.

The bridge geometry and the structural system are given in Figure 2. The cross sectional properties were taken from the experimental evidence. A modulus of elasticity $\mathrm{E}=210 \mathrm{GPa}$ and a yield strength fsy $=264 \mathrm{MPa}$ were considered based on the original construction drawings.

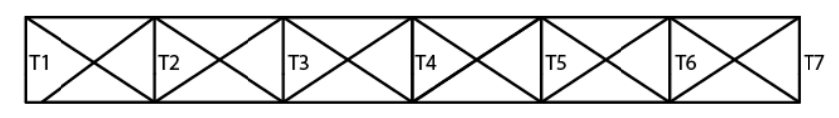

ROOF PLAN
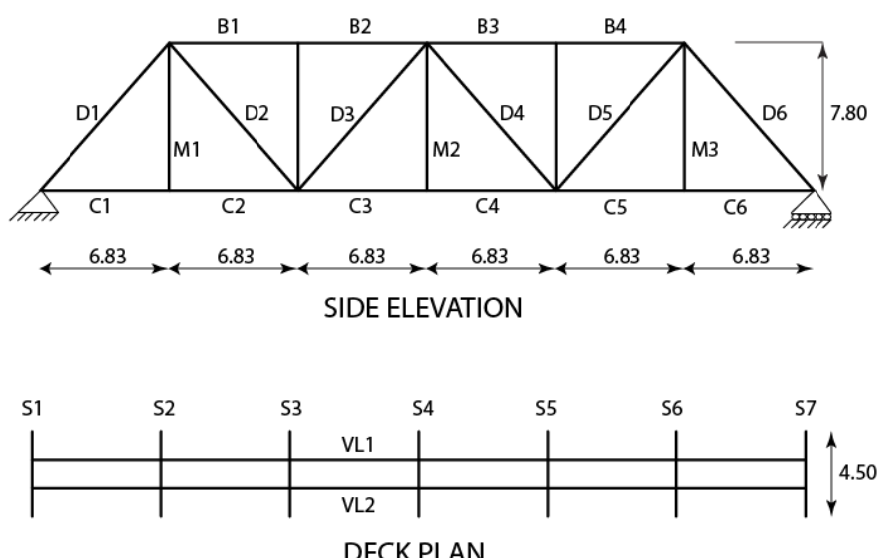

Figure 2. Principal geometry of the bridge.

\section{ACTIONS ON STRUCTURE DUE TO TRAIN LOADING}

The worst case load effects are generated in the structure during the passage of fully loaded ore trains. A number of different wagons types were observed on the railways and a comparison of the mass distribution of the various cargo wagons was carried out. It was found that the GDE type wagon has the greatest load effect. The weight is $175 \mathrm{kN}$ and payload is $795 \mathrm{kN}$ giving a total load of $970 \mathrm{kN}$ spread onto four axles. The bridge fatigue effects were analysed assuming this worst case GDE wagons with axle arrangement and loading as shown in Figure 3.
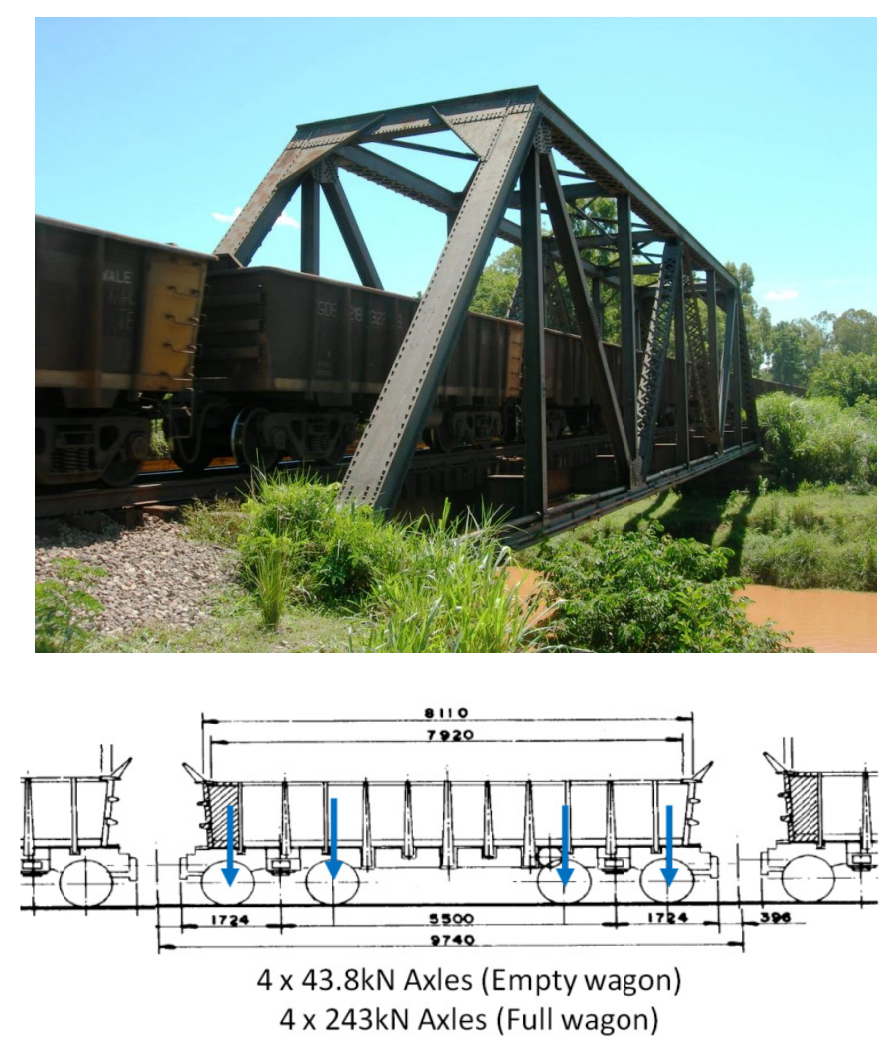

Figure 3. Standard ore wagon loading and geometry ( $\mathrm{mm})$.

A series of dynamic wheel loads measured on the tracks during the passage of a long ore train at a velocity of $32 \mathrm{Km} / \mathrm{h}$ revealed an average axle load of $228 \mathrm{kN}$ which is slightly less than that given in the previous figure and therefore conservative. This was performed by instrumenting a section or rail before the bridge with strain gauges (Fig. 4) and calibrating the measured strain readings against axles of known weight to enable recording of all train axles.

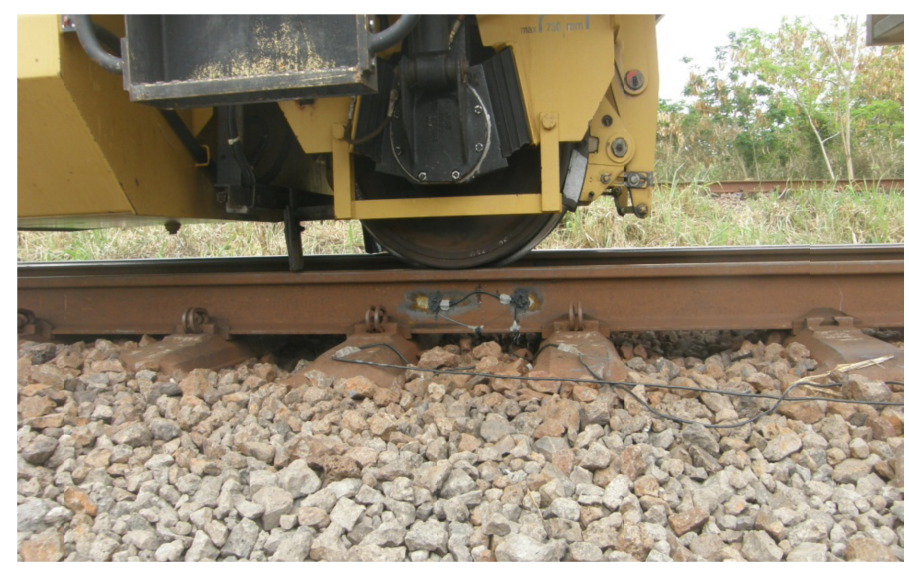

Figure 4. Instrumentation for measurement of axle loads on track.

The locomotive selected for this study is the DASH 9M model shown in Figure 5 with a total mass of 160 tonnes. There are generally two loco- 
motives required for the long (approximately 200 wagon) ore trains.

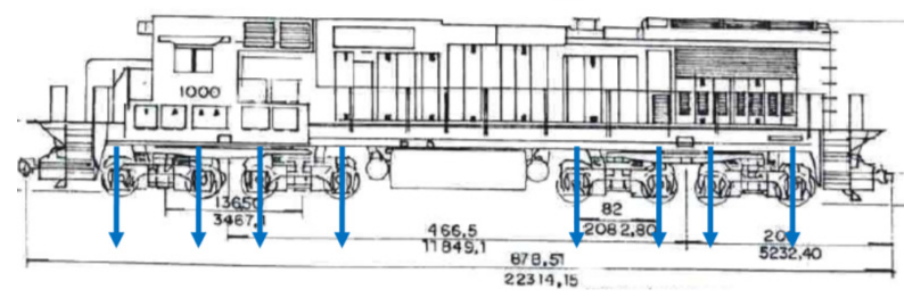

$8 \times 200 k N$ Axles

Figure 5. Locomotive loading and geometry (mm).

\section{STRUCTURAL ANALYSIS AND DETERMINATION OF ACTION EFFECTS}

A linear elastic model of the structure was created using the Oasys GSA structural analysis software package as shown in figure 6 .

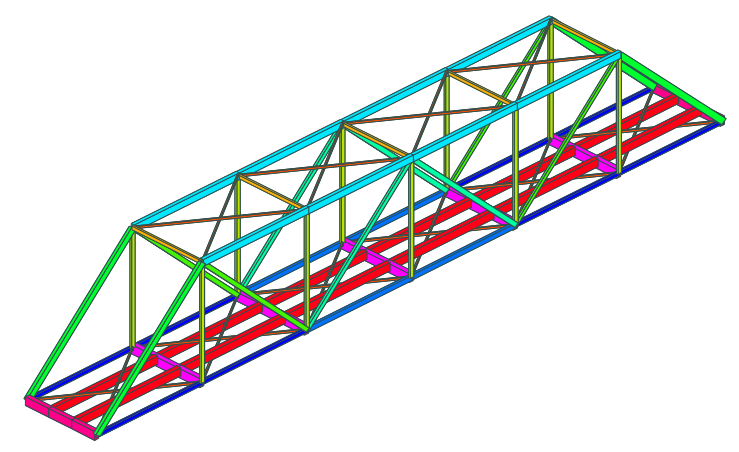

Figure 6. Three-dimensional view of structural model.

The bridge is supported on the four outermost corners with no longitudinal rotational restraint at either end i.e. a simply supported pin-roller detail. One end of the bridge is fixed in displacement in the vertical, transverse and longitudinal directions while the other end features only vertical and transverse restraint to model the sliding bearing.

\subsection{Train loading application}

The GSA software was programmed to simulate the crossing of a full 200 wagon ore train over the bridge and calculating the static stresses generated in the bridge as the wheel loads are moved along the deck. Figure 7 illustrates the vehicle load step application process. An increment spacing of $1 \mathrm{~m}$ was chosen for the calculation of wheel load stresses. The results were then compiled into worst case envelopes for each member.

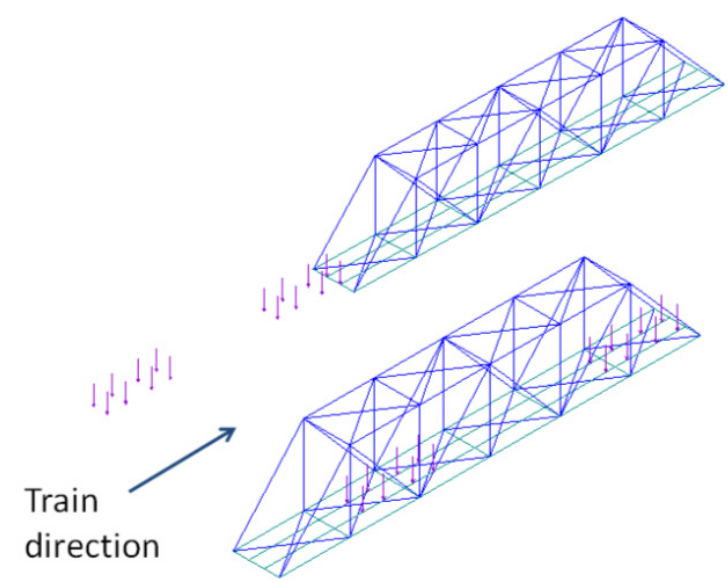

Figure 7. Train load step application process.

\subsection{Action effects}

The gravity load effects due to self-weight of structure and the weight of sleepers and rails are included in the model. The calculation for the full ore trains is based on 200 full GDE wagons.

Figure 8 graphically illustrates the axial stresses in the bridge under the combined effect of permanent actions and the static load of full ore trains. The results indicate that the tensile diagonal members to be most highly stressed elements of the structure.

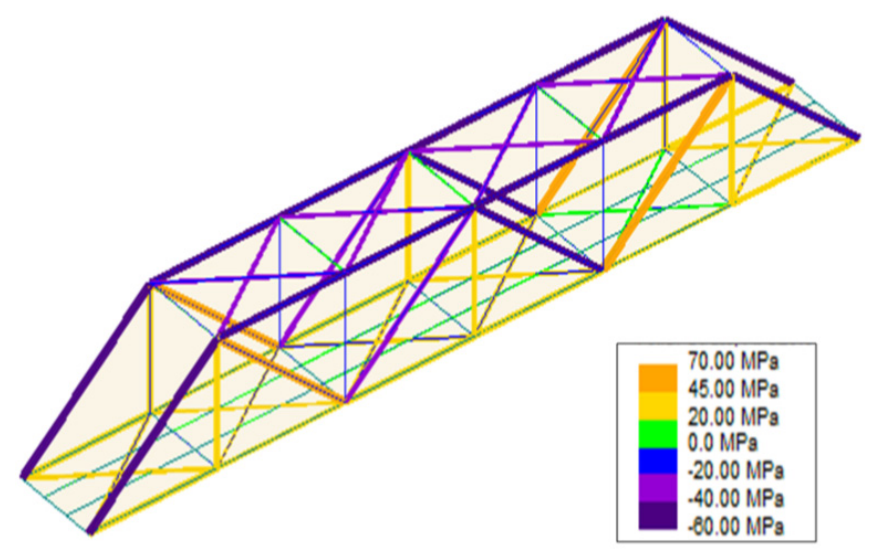

Figure 8. Envelope of axial stress in bar members due to full ore train loads and bridge self-weight.

\subsection{Dynamic train loading effects}

The computer described in the previous sections assumes a perfectly smooth transition of the train over the bridge and makes no allowance for dynamic enhancement of the static loads due to unevenness and irregularities in the wheels, rails and bridge. An initial approximation of the dynamic amplification of static loads for assessment purposes can be found in EN 1991-2 Appendix D. This provides a series of formulae to calculate a dynamic enhancement factor for static loads acting on different structural elements of railway bridges. 
The dynamic enhancement factors for the main truss girders and deck members were obtained considering a maximum ore train velocity of $50 \mathrm{~km} / \mathrm{h}$. The stresses calculated in each of the elements in the previous sections have been increased by the factors shown in the table 1, for fatigue and ULS assessment.

Table 1: Dynamic enhancement factors.

\begin{tabular}{lccc}
\hline Members & $L_{\Phi}(\mathrm{m})$ & $\Phi$ (Fatigue) & $\Phi$ (Real trains) \\
\hline Steel truss & 41 & 1.04 & 1.07 \\
\hline $\begin{array}{l}\text { Deck internal } \\
\text { cross girders }\end{array}$ & 9 & 1.11 & 1.25 \\
\hline $\begin{array}{l}\text { Deck end cross } \\
\text { girders }\end{array}$ & 3.6 & 1.17 & 1.4 \\
\hline Deck stringers & 4.5 & 1.16 & 1.38 \\
\hline
\end{tabular}

\section{SAFETY VERIFICATIONS}

\subsection{Structural safety}

All of the bridge members were first verified with respect to ultimate limit state. All bridge members were found to have sufficient structural safety when considering commonly used partial safety factors for actions and resistances i.e. load factor of 1.50 for train loading as leading action and resistance factor 1.15 for riveted steel sections. The determinant tensile diagonals had a degree of compliance $n=R_{d} / E_{d}=1.90$ with $R_{d}$ and $E_{d}$ being the examination value for ultimate resistance and action effect respectively. The most heavily stressed deck members, the longitudinal girders, showed $n=R_{d} / E_{d}=2.11$ which suggests the bridge structure is safe under current ultimate loads and shows even considerable reserves. All the members of the bridge behave elastically under extreme service loads.

\subsection{Fatigue safety verification}

In view of updating these bridge structures for higher traffic loads, the fatigue safety is likely to be determinant. The fatigue capacity and remaining fatigue life have been analysed in the following. Stress histories in the various members are first determined numerically as shown in Figure 9. The stress ranges are based on the worst case train loading as described above with the stress ranges increased by the dynamic factors shown in the table 1 .

\subsection{Fatigue damage accumulation}

In order to check the steel bridge behavior in relation to fatigue, the accumulate damage was calculated for the truss members considering a period of 70 years, 1940-2010. In addition, an estimate was made for 50 years into the future based on current loads (20102060) assuming the same traffic loading.

The truss and deck members were analyzed with the S-N curve occurring to the fatigue category 80 and 71 respectively as shown in the Figure 10. These curves take account of secondary stress effects in members and assume that the connections are modeled as pinned for the analyses.

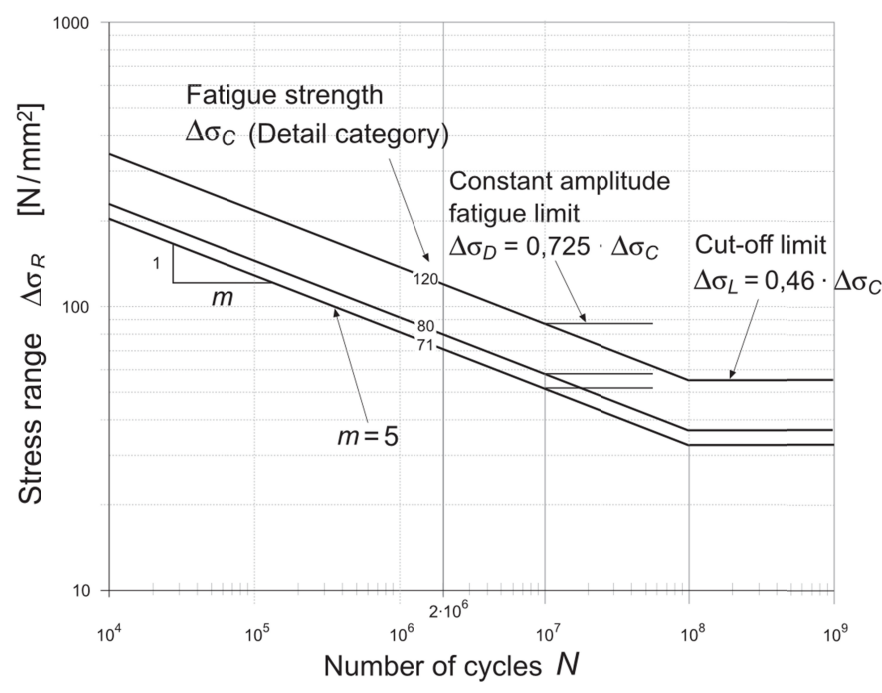

Figure 10. S-N curve used in study (SIA 269/3, 2011).

As visual inspections verified that there were no cracks on the elements it was possible to apply Linear Damage Theory. The calculation of the accumulated damage is obtained by means of Linear Damage Theory, resulting from multi-stage spectrum ( $\left.\Delta \sigma_{i}, n_{i}\right)$ and can be expressed by the linear sum (Miner sum).

The Palmgren Miner sum is given by $\sum\left(\frac{n_{i}}{N_{i}}\right)$ in which $N_{i}$ is the number of the load cycles at the stress level $\Delta \sigma_{i}$. A value of equal to 1 indicates that the element has theoretically reached the end of its fatigue life. 

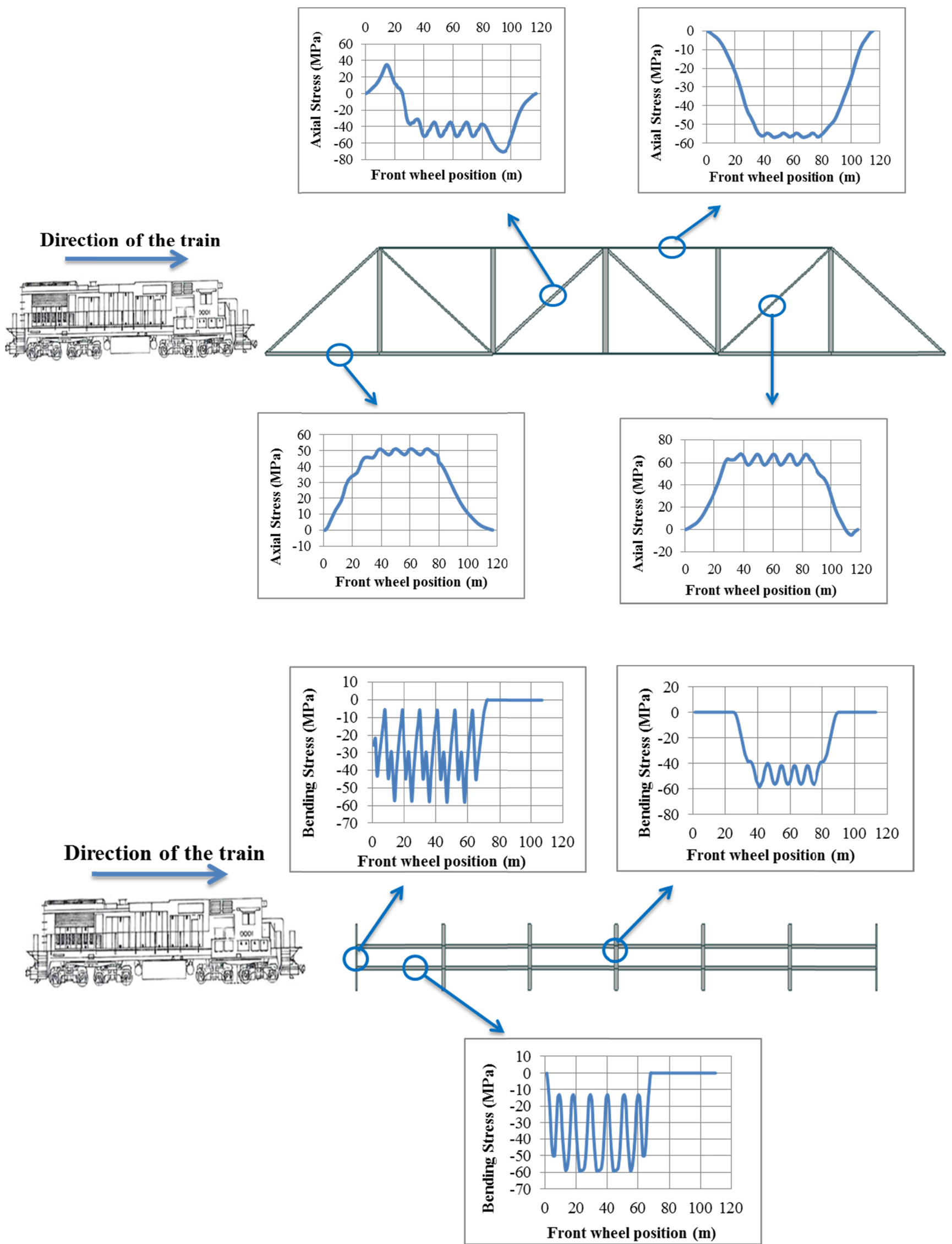

Figure 9. Fatigue stress cycles in the truss (top) and deck (bottom) members under passage of 10 full ore wagons. 
The stress ranges $\left(\Delta \sigma_{i}\right)$ during train passage were analysed by means of the Rainflow counting method (Stephens et al. 2001). Stress ranges greater than 58 and $51.5 \mathrm{MPa}$ (fatigue resistance limit under constant amplitude) on the S-N curves are considered to reduce fatigue life of truss and deck members respectively. The frequencies of full ore wagon trains (with 200 wagons) are a total of approximately 8740 trains per year (considering 24 trains per day, 7 days of train operation per week and 52 weeks of train operation per year). This data was considered for fatigue analyses for the past 70 years and also for 50 years into the future, ignoring in a first step future increase in train loads. Truss and deck members which show stress cycles exceeding the fatigue limit and therefore experiencing fatigue damage are given in Table 2. Further work is required to determine the future trends in traffic volume.

Table 2. Summary of fatigue stress ranges in the truss and deck members.

\begin{tabular}{lcc}
\hline Members & $\begin{array}{c}\Delta \sigma \\
(\mathrm{MPa})\end{array}$ & $\begin{array}{c}\Phi \Delta \sigma \\
(\mathrm{MPa})\end{array}$ \\
\hline D2/D5 & 68 & 71 \\
\hline $\begin{array}{l}\text { Deck internal } \\
\text { cross girders }\end{array}$ & 53 & 59 \\
\hline $\begin{array}{l}\text { Deck end cross } \\
\text { girders }\end{array}$ & 50 & 59 \\
\hline Deck stringers & 51 & 60 \\
\hline
\end{tabular}

The members were found to have sufficient capacity even for another 50 years of the current loading although the fatigue load vehicle (GDE wagon) was quite conservative as its mass was far in excess of the other types of wagons observed on the tracks with significantly lower weights. Therefore the real fatigue damage will be less than that calculated.

The majority of the members experience insignificant stress cycles under the continuous passage of train wheels of a long train once the initial loading of the bridge was complete. One important assumption was that there are no empty wagons present in the middle of such long trains as this would introduce additional high stress cycles.

\section{DEVELOPMENT OF A FATIGUE DAMAGE MONITORING SYSTEM}

A monitoring system was implemented to verify the structural analysis results. The monitoring locations are highlighted in Figure 11. The system includes accelerometers, strain gauges and LVDT's.

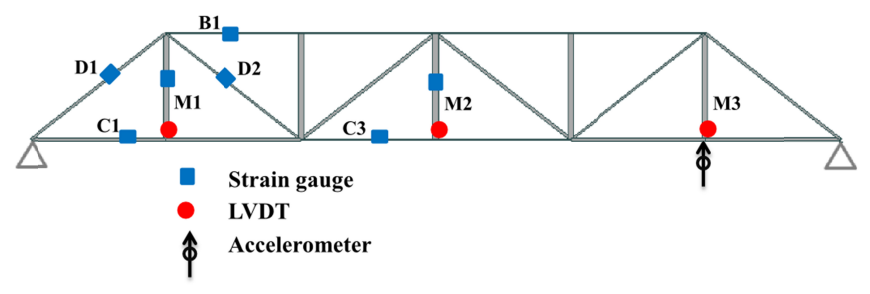

Figure 11. Locations of various sensors on bridge.

In order to verify the dynamic response of the structure a series of accelerometers are located on the structure as shown in Figure 12.

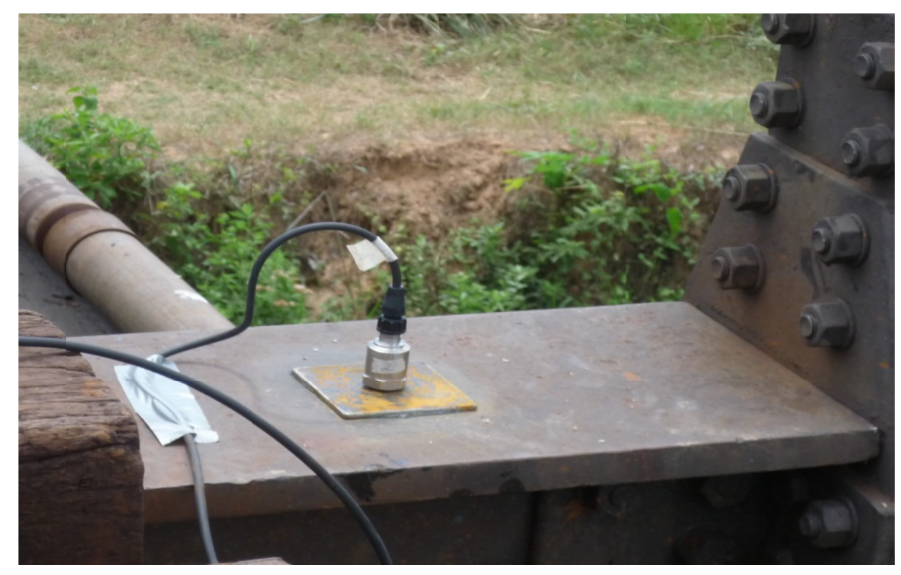

Figure 12. Accelerometer for investigation of dynamic effects.

The principal results from the monitoring system are the strains in the members which are directly applicable for fatigue and ULS assessment. Clusters of strain gauges are positioned at critical point in the structure as shown in Figure 13.

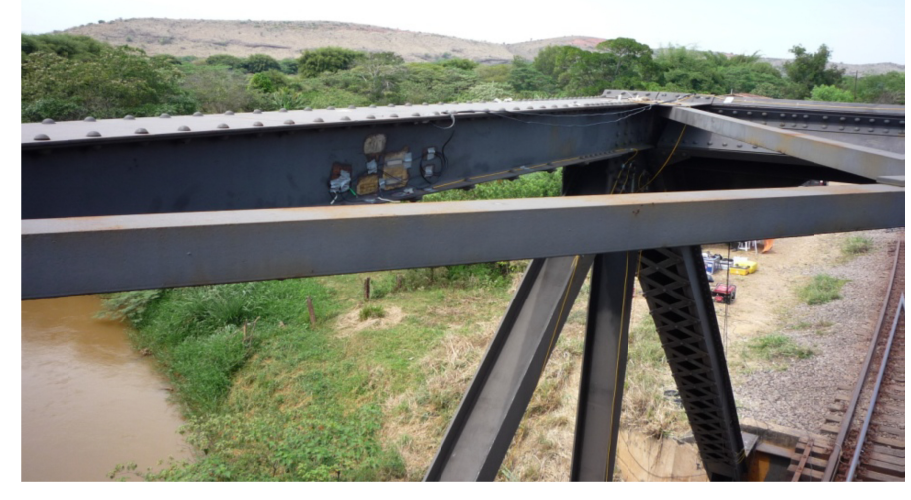

Figure 13. Strain gauges on top chord of truss. 
The next phase of work involves updating and refinement of the structural models based on the measured data in addition to detailed assessment of the structural safety of the connections. Subsequently, long term monitoring, i.e. typically over 12 months, will be performed and collected data analysed for updating the fatigue safety verifications presented above.

\section{CONCLUSIONS}

First results of a study on fatigue examination of a standard bridge type of a railway line are presented. All of the members of the riveted steel truss structure were found to be safe under the various limit states. The level of stress ranges found in the truss and deck members due to fatigue loading are low. The deck and two truss members experience small fatigue damage. The bridge structure has thus significant reserves in capacity which makes an increase in axle loads in the future feasible.

\section{REFERENCES}

Brühwiler, E., Lüchinger, P., Lang, T. \& Vogel, T. 2011. Swiss standards for existing structures, Structural Engineering International, IABSE, Zurich.

EN 1991-2:2003. Eurocode 1: Actions on structures - Part 2: Traffic loads on bridges. European Committee for Standardisation.

Standard SIA 269, 2011. Existing structures - Basis for examination and interventions. Swiss Standard SN 505269, Swiss Society of Engineers and Architects (SIA), Zurich.

Standard SIA 269/3, 2011. Existing structures - Steel structures. Swiss Standard SN 505 269/3, Swiss Society of Engineers and Architects (SIA), Zurich.

Stephens, R.I., Fatemi, A. Stephens, R.R. \& Fuchs H.O. 2001. Metal Fatigue in engineering. Wiley, New York. 